\title{
Footprints of past intensive diversification and structuring in the genus Zelkova (Ulmaceae) in south-western Eurasia
}

\author{
Camille Christe ${ }^{1,3}$, Gregor Kozlowski ${ }^{3,4}$, David Frey ${ }^{3,5}$, Sébastien Bétrisey ${ }^{3}$, \\ Elmira Maharramova ${ }^{6}$, Giuseppe Garfi ${ }^{7}$, Stergios Pirintsos ${ }^{8,9}$ \\ and Yamama Naciri ${ }^{1,2 \star}$
}

${ }^{1}$ Plant Systematics and Biodiversity Laboratory, Molecular Phylogeny and Genetics Unit, Conservatoire et Jardin botaniques de la Ville de Genève, $\mathrm{CH}-1292$ Chambésy, Geneva, Switzerland, ${ }^{2}$ Plant Systematics and Biodiversity Laboratory, University of Geneva, CH-1292 Chambésy, Geneva, Switzerland, ${ }^{3}$ Department of Biology and Botanic Garden, University of Fribourg, CH-1700 Fribourg, Switzerland, ${ }^{4}$ Natural History Museum, CH-1700 Fribourg, Switzerland, ${ }^{5}$ Conservation Biogeography Group, Department of Geosciences, University of Fribourg, CH-1700 Fribourg, Switzerland, ${ }^{6}$ Institute of Botany, Azerbaijan National Academy of Sciences, AZ-1073 Baku, Azerbaijan, ${ }^{7}$ National Research Council (CNR), Institute of Biosciences and Bioresources, I-90129 Palermo, Italy, ${ }^{8}$ Department of Biology, University of Crete, GR-71409 Heraklion, Crete, Greece, ${ }^{9}$ Botanical Garden, University of Crete, GR-74100 Rethymnon, Crete, Greece

${ }^{*}$ Correspondence: Yamama Naciri, Laboratoire de Systématique Végétale et Biodiversité,

Unité de Phylogénie et Génétique Moléculaires, Conservatoire et Jardin botaniques,

1292 Chambésy, Geneva, Switzerland.

E-mail: Yamama.Naciri@ville-ge.ch

\begin{abstract}
Aim To elucidate the phylogeographical patterns in three Cenozoic relict species: Zelkova sicula, Z. abelicea and Z. carpinifolia (Ulmaceae).

Location Sicily, Crete and Transcaucasia.

Methods Two chloroplast loci (trn H-psbA and $\operatorname{trn} \mathrm{L})$ and the nuclear ribosomal markers ITS1 and ITS2 were sequenced for 154 samples collected from 14 populations of $Z$. abelicea, 16 populations of $Z$. carpinifolia, and the two known populations of $Z$. sicula. We obtained georeferenced data, calculated median joining networks and carried out diversity analyses. A few ex situ samples collected from botanical gardens, of the East Asian species Zelkova serrata, Z. schneideriana and Z. sinica, were also analysed for comparative purposes.
\end{abstract}

Results High levels of variability were found in the chloroplast markers within $Z$. carpinifolia (15 haplotypes) and Z. abelicea (33 haplotypes), in association with strong phylogeographical structure. Conversely, $Z$. sicula was characterized by low diversity, with each population exhibiting a single haplotype. Lower variability was found for ITS1 and ITS2 within Z. carpinifolia and Z. abelicea (13 and 7 ribotypes per species, respectively), with $Z$. carpinifolia showing a high proportion of populations with no intragenomic polymorphism. In the triploid and clonal $Z$. sicula, all individuals displayed intragenomic polymorphism and seven ribotypes were identified.

Main conclusions The chloroplast diversity of Z. abelicea and Z. carpinifolia suggests a very ancient history of diversification and structuring, with footprints of past expansions and more recent bottlenecks. Zelkova sicula has had a history of severe isolation and is likely to be of hybrid origin.

\section{Keywords}

Chloroplast markers, Crete, internal transcribed spacer, phylogeography, Sicily, Transcaucasia, Zelkova abelicea, Zelkova carpinifolia, Zelkova sicula.

\section{INTRODUCTION}

Climatic oscillations during the Quaternary had dramatic effects on the distributions of species worldwide (Hewitt, 2000). South-western Eurasia, and especially Europe, was greatly affected by the glaciations (Connor, 2009), because both the Mediterranean Sea and east-west-orientated mountains prevented many species from migrating southwards. Several genera of the prominent Cenozoic tree flora vanished from the European continent or only survived in isolated and disjunct refugia of the Transcaucasian region, in the Balkan Peninsula and on Mediterranean islands (Milne \& Abbott, 2002; Quézel \& Médail, 2003).

Species of Zelkova Spach (Ulmaceae) were important elements of the vast forests that prevailed throughout the Northern Hemisphere during much of the Cenozoic Period (Mai, 1995; Fineschi et al., 2004; Walker et al., 2012). Today, the genus comprises six species with disjunct distribution 
patterns (Denk \& Grimm, 2005): three in eastern Asia [Zelkova serrata (Thunb.) Makino; Zelkova schneideriana Hand.Mazz.; and Zelkova sinica C. K. Schneid.], one in southwestern Asia [Zelkova carpinifolia (Pall.) C. Koch] and two on the Mediterranean islands of Sicily (Zelkova sicula Di Pasq., Garfì \& Quézel) and Crete [Zelkova abelicea (Lam.) Boiss.]. The oldest fossils attributed to Zelkova date from the early Eocene $(55 \mathrm{Ma})$ in western North America, where the genus is extinct today (Burnham, 1986).

Phylogeography, using chloroplast and mitochondrial markers, has mostly focused on the Quaternary and the influence of the cycles of glaciation on species distribution and structure (Schönswetter et al., 2005; Terrab et al., 2008). Phylogeography has, however, also been used to document more ancient patterns (Petit et al., 2005a; Rodríguez-Sánchez et al., 2009), with some of them presumably dating as far back as the early Miocene (Magri et al., 2007). The retrieval of ancient patterns may be specific to tree species, which are assumed to evolve more slowly than herbaceous plants and shrubs (Petit \& Hampe, 2006). Zelkova trees live for centuries (Fazan et al., 2012), which is a good indication that ancient patterns might be recovered using molecular markers.

A few phylogenetic and biogeographical studies have already been carried out on Zelkova (Fineschi et al., 2002, 2004; Denk \& Grimm, 2005; Fukatsu et al., 2012), but these studies had small sample sizes or weak representation of wild populations. Our phylogeographical analysis, based on $\operatorname{trn} \mathrm{H}-$ $p s b \mathrm{~A}, \operatorname{trn} \mathrm{L}$ and internal transcribed spacer regions 1 and 2 (ITS1 and ITS2), is the first to use a comprehensive sampling of natural populations from nearly all the disjunct regions where $Z$. abelicea, $Z$. carpinifolia and $Z$. sicula presently grow. We aimed to assess the diversity within and among species using DNA from two cellular compartments that have different modes of inheritance and trace different histories (Petit et al., 2005b). For comparative purposes, we added specimens of the three East Asian Zelkova species, using ex situ collections.

The following questions were addressed: (1) What are the relationships of the three south-western Eurasian species, and how are they related to the East Asian species? (2) What are the phylogeographical patterns of the south-west Eurasian species, and what do they convey about the colonization and diversification patterns within species? (3) Do the chloroplast and nuclear loci give congruent information?

\section{MATERIALS AND METHODS}

\section{Study group}

Zelkova abelicea is endemic to Crete (Greece); it has a fragmentary distribution in the four main mountain regions of Crete (Lefka Ori, Psiloritis, Dikti and Thrypti), between 900 and $1800 \mathrm{~m}$ a.s.l., which corresponds to the upper timberline (Kozlowski et al., 2014). It grows mainly on north-facing slopes or in and around rocky river-beds and gullies which remain moist during dry summers (Egli, 1997; Søndergaard \& Egli, 2006). The species is highly endangered through habitat fragmentation and destruction, overgrazing, fire and water stress (Phitos et al., 1995; Søndergaard \& Egli, 2006; Kozlowski et al., 2014).

Zelkova carpinifolia grows in the Transcaucasian countries of western Asia: Georgia, Armenia, Azerbaijan, Iran and Turkey (Güner \& Zielinski, 1998). This area is considered to be one of the most important refugial zones of the Cenozoic relict flora in south-western Eurasia (Mai, 1995; Milne \& Abbott, 2002). Despite having a relatively wide distribution range, Z. carpinifolia is rare and/or threatened in many regions (Davis, 1982; Kozlowski et al., 2012). Two additional taxa have been recognized: Z. carpinifolia subsp. yamraensis Anşin \& Gercek was described from Trabzon in northeastern Turkey, and some populations from southern Azerbaijan have been distinguished as Z. hyrcana Grossh. \& Jarm. None of these putative taxa have been investigated using molecular methods.

Zelkova sicula, discovered in 1991, is endemic to southeastern Sicily (Di Pasquale et al., 1992). The species has been identified as the most threatened in the genus, with only two known populations and a total of 1800 individuals (Garfi, 2006). Zelkova sicula is triploid and produces sterile seeds (Garfi et al., 2011; G. Garfi, Institute of Biosciences and Bioresources, Palermo). Although several studies have been carried out on one population of this taxon (Nakagawa et al., 1998; Fineschi et al., 2002; Garfi et al., 2002), the phylogenetic position of $Z$. sicula has not yet been elucidated.

\section{Sampling}

Leaf material of $Z$. abelicea, Z. carpinifolia and Z. sicula was retrieved from up to five individuals per population for a total of 154 trees. The sampling included 14, 16 and 2 populations, respectively; 19 ex situ samples of Z. serrata, $Z$. schneideriana and Z. sinica collected from botanical gardens were also used (see Appendix S1 in Supporting Information). All voucher specimens (one individual per population) were deposited in the herbarium of the Natural History Museum in Fribourg, Switzerland.

\section{DNA extraction, amplification and sequencing}

Total genomic DNA was extracted using the NucleoSpin Plant II kit (Macherey-Nagel, Düren, Germany). One cpDNA spacer (trnH-psbA; Shaw et al., 2005), one cpDNA intron (trnL; Taberlet et al., 1991) and two nrDNA markers (ITS1: Denk et al., 2002; ITS2: White et al., 1990) were used. Amplifications were carried out in a Biometra thermocycler (Göttingen, Germany) as detailed in Appendix S2. The sequencing reactions were performed using BigDye Terminator v3.1 Cycle Sequencing Kit and run on an ABI 377 automated sequencer (Applied Biosystems, Foster City, CA, USA). For ITS1, sequencing reactions were performed using the GenomeLab DTCS Quick Start Kit and run on a 
GenomeLab GeXP automated sequencer (Beckman Coulter, Fullerton, CA, USA).

Some samples of Z. sicula produced illegible ITS2 sequences, and required cloning. The PCR products were ligated into the pGEM-T plasmid of the Promega pGEM-T Vector System I kit (Promega, Fitchburg, WI, USA). The ligated products were used to transform JM109 competent cells (Promega, Fitchburg, WI, USA) and five clones per PCR product were subsequently sequenced using the same protocol as before. No legible sequences were obtained for ITS1 in population A2 of $Z$. sicula despite several attempts.

\section{Data analyses}

All sequences were assembled with Sequencher (GeneCodes Corporation, Ann Arbor, MI, USA) and manually aligned in BioEdit 7.0.3.5 (Hall, 1999). The cpDNA sequences were clustered into haplotypes on the basis of the aligned sequences. Indels and inversions were coded manually following Simmons \& Ochoterena (2000) then used in all analyses, as they provide relevant phylogeographical information (Ingvarsson et al., 2003). For ITS1 and ITS2, ambiguous positions were sometimes found; in order to determine the sequence phase in single individuals, we used the software PHASE 2.1 (Stephens et al., 2001). The inferred haplotypes were named ribotypes and used in further analyses. In order to exclude putative pseudogenes, the GC content of each ribotype was computed using BIoEDIT, and ITS2 ribotypes were checked for the presence of the two conserved motifs M2 (5'-GAATTGCAGAATCC-3') and M3 (5'-TTTGAACGCA-3'; Hřibová et al., 2011). Haplotype richness and ribotype richness $(R s)$ were computed for each species using the rarefaction method (Petit et al., 1998) in order to account for differences in sampling size, using $n=10$ for the chloroplast data and $n=8$ for the nuclear data. The chloroplast haplotypes and ITS genotypes sequences were deposited in GenBank (accession numbers JX399087-JX399147, JX110824-JX110837 and KF561728-KF561819).

Linkage disequilibrium between the two chloroplast loci was checked using Fisher's exact test, prior to their combination as chloroplast haplotypes. The haplotype diversity $(h)$ and nucleotide diversity ( $\pi$; Nei, 1987) were estimated for $Z$. abelicea, Z. carpinifolia and Z. sicula, and tested for deviation from neutral evolution using Tajima's $D$ (Tajima, 1983) and Fu's $F_{S}(\mathrm{Fu}, 1997)$ statistics. Analyses of molecular variance (AMOVAs; Excoffier et al., 1992) were conducted to assess genetic differentiation among populations $\left(F_{\mathrm{ST}}\right)$ or groups of populations $\left(F_{\mathrm{CT}}\right)$ using pairwise differences as the measure of genetic distance between haplotypes. Mantel tests were computed for Z. abelicea and Z. carpinifolia to check for the significance of isolation by distance between populations, using one matrix of $F_{\mathrm{ST}} /\left(1-F_{\mathrm{ST}}\right)$ values and one of either geographical distances between populations or their natural logarithms (Rousset, 1997). Mismatch distributions were computed within species and within regions, and the observed pattern was compared to those obtained under a sudden demographic expansion or a spatial expansion scenario. Goodness of fit, based on the sum of the squared differences (SSD) between the observed and the simulated data, was used as a statistical test to accept or reject a given scenario (Excoffier et al., 2006). Each time a scenario could not be rejected at the $5 \%$ level, an estimate of the parameter of the spatial or demographic expansion was obtained. For a demographic expansion, a stationary haploid population at equilibrium is assumed to have suddenly passed from $N_{0}$ to $N_{1}$ individuals $T$ generations ago. For a spatial expansion, it is assumed that a population of $N_{0}$ individuals expanded in space $T$ generations ago as an infinite number of demes of size $N$ that exchange migrants with other demes (Ray et al., 2003; Excoffier, 2004). The estimated parameters are $\theta_{0}=2 \mu N_{0}, \theta_{1}=2 \mu N_{1}$ and $\tau=2 \mu T$. Because the chloroplast mutation rate is unknown for Zelkova, only $\tau$ is given to allow comparisons among species, assuming that the mutation rate is the same among species. All former analyses were performed using ARLequin 3.1.5.2 (Excoffier et al., 2006), and significance tests were conducted using 10,000 permutations.

The median joining network (MJN) of combined chloroplast haplotypes was drawn using the software NETwORK (Bandelt et al., 1999). Site mutations, indels and inversions were equally weighted. As no Asian species could be sequenced for ITS1, GenBank accessions were used instead for Z. serrata and Z. schneideriana. Consequently, ITS1 and ITS2 sequences were not combined for these species and two different MJNs were built using the same rules as before. The geographical distribution of chloroplast haplotypes was visualized using ArcMap GIS.

\section{RESULTS}

\section{Chloroplast haplotype diversity and population differentiation}

From a 1530-bp alignment, 91 polymorphic sites and 58 combined haplotypes were detected for the two cpDNA loci in the 173 individuals analysed (Appendix S3). Only two haplotypes were shared between species, both of them among East Asian species (Appendix S3).

Two of the three East Asian species display equivalent diversities, with four haplotypes each ( $Z$. serrata and $Z$. schneideriana), followed by $Z$. sinica, with two haplotypes. Zelkova abelicea, Z. carpinifolia and Z. sicula exhibit 33, 15 and 2 haplotypes, respectively, all of which are speciesspecific (Appendix S3). The lowest overall gene diversity $(h)$ is found in Z. sicula, and the highest in Z. abelicea and Z. carpinifolia (Table 1). Zelkova sicula also displays the lowest nucleotide diversity, while $Z$. carpinifolia has the highest (Table 1). Haplotype richness was equivalent in $Z$. abelicea and $Z$. carpinifolia ( $R s=7.8$ and $R s=7.3$, respectively), but higher than the two haplotypes found in $Z$. sicula.

Of the 32 populations of Z. abelicea, Z. carpinifolia and Z. sicula, 22 are polymorphic: 13 in Z. abelicea and 9 in 


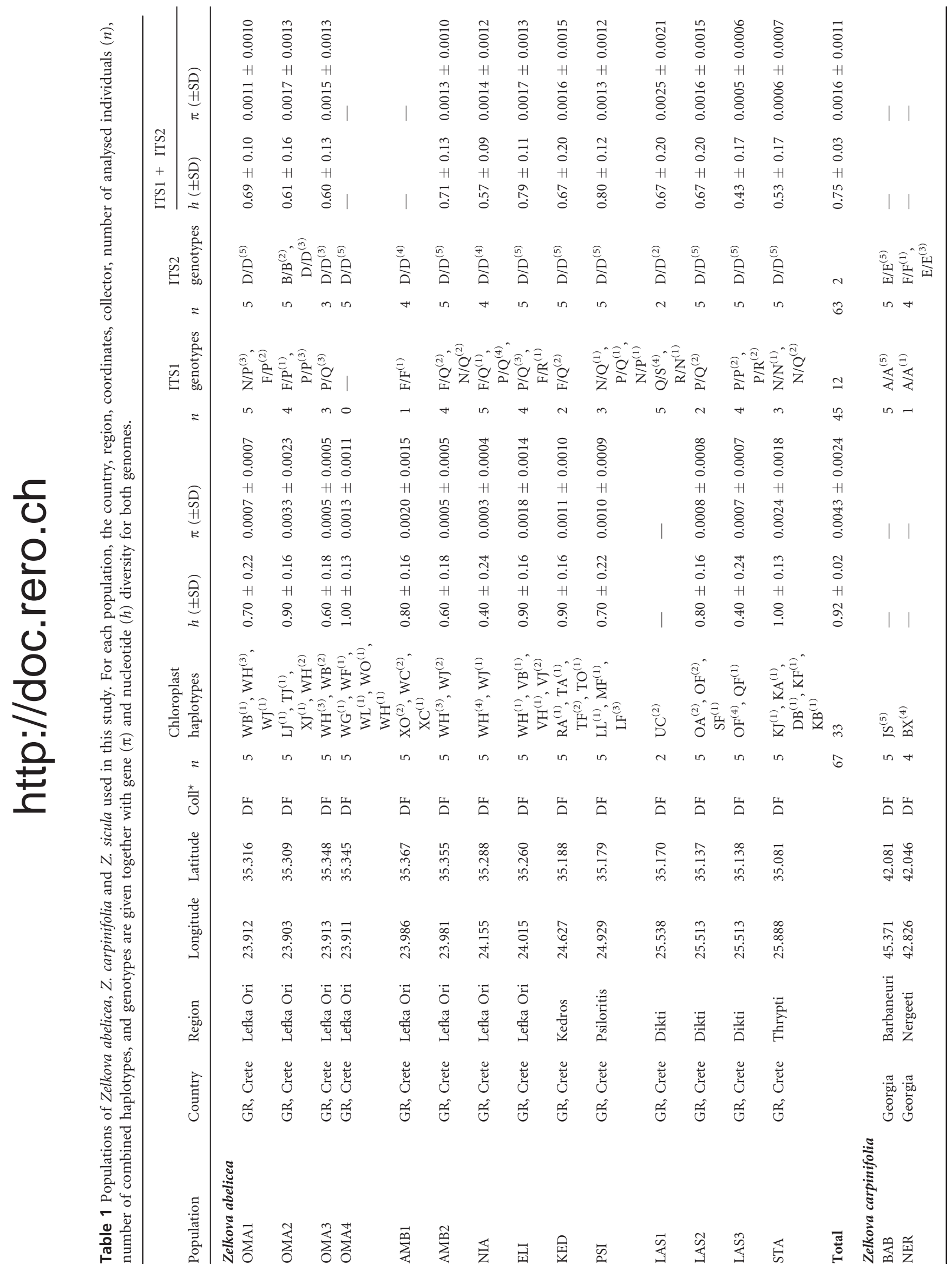




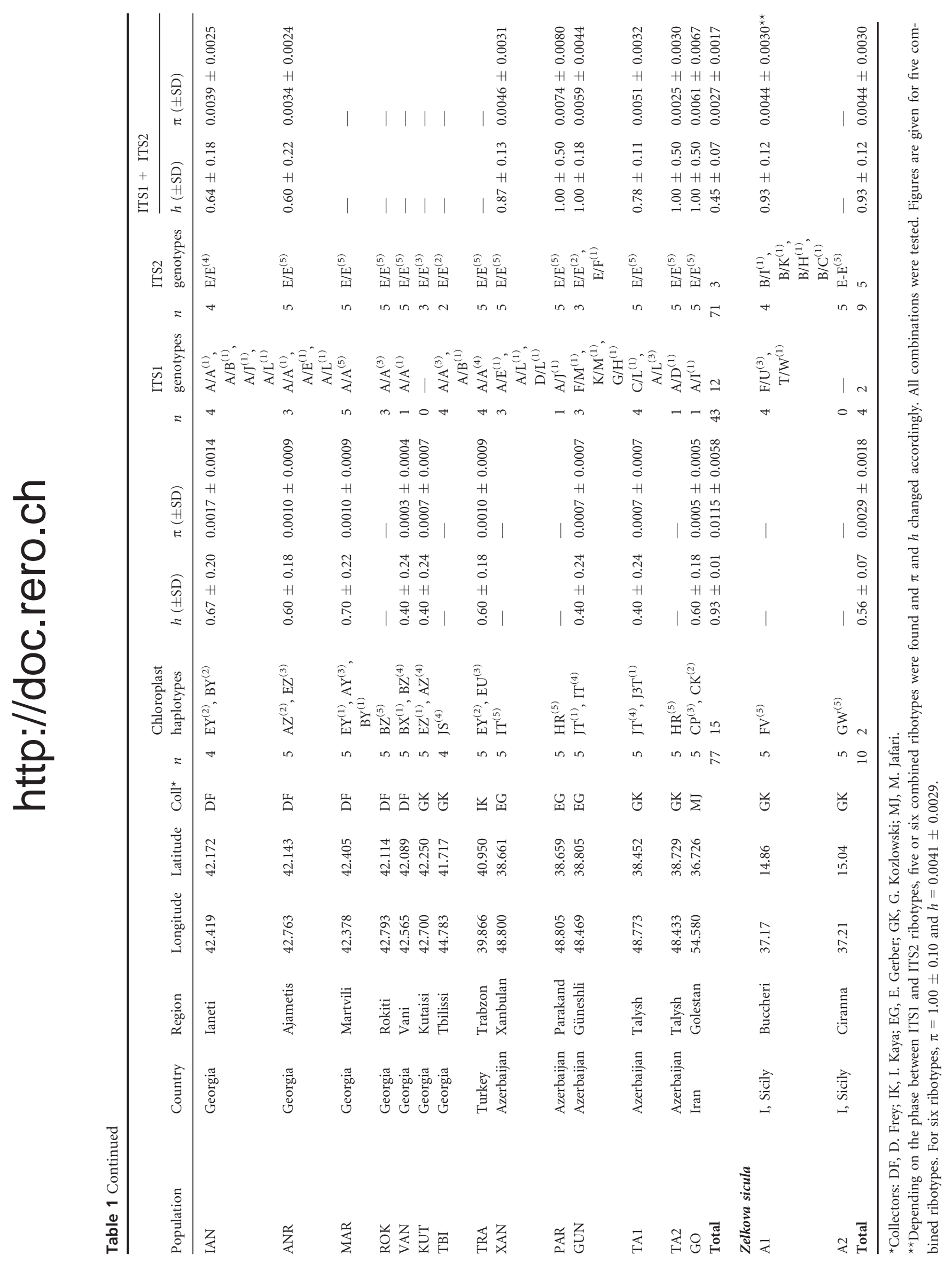


Z. carpinifolia (Table 1). For Z. carpinifolia, both neutrality tests were non-significant or nearly so $(D=1.196, P=0.090$; $\left.F_{S}=7.279, P=0.049\right)$. For $Z$. abelicea, the neutrality tests gave contrasting results, with a non-significant Tajima's $D$ $(D=0.558, \quad P=0.251)$ and a highly significant $F_{S}$ $\left(F_{S}=-17.759, P=0.000\right)$, indicating that more haplotypes were recorded than would have been expected under neutrality.

The haplotype MJN is clustered into groups separated by many mutations (Fig. 1a). The haplotypes belonging to $Z$. abelicea show reticulate evolution and are grouped corresponding to the major Cretan mountains (Fig. 1c). Haplotypes of $Z$. carpinifolia are clustered into two groups, separated by a minimum of 19 mutations. The haplotypes of the first group (AY, AZ, BX, BY, BZ, EU, EY and EZ; Fig. 1d) are found only in the western populations. The second group of haplotypes (JS, JT, J3T, IT and HR) is found in the five eastern and the two central populations, whereas haplotypes $\mathrm{CP}$ and $\mathrm{CK}$ are seen in the population from Golestan (north-eastern Iran). The only two known popula- tions of Z. sicula display one haplotype each (FV and GW; Fig. 1b), located between those of $Z$. carpinifolia and $Z$. abelicea. The eight haplotypes found in the three East Asian species (Z. sinica, Z. serrata and Z. schneideriana; SH4E, YD, YE, ZD, ZE, Z2E, Z3E and Z5E) are grouped together in a different part of the network which is joined to the first cluster of $Z$. carpinifolia.

$F_{\mathrm{ST}}$ is very high within species, and is significant for Z. abelicea and Z. carpinifolia (Table 2). For these species, the populations were further clustered into four groups according to geography (Fig. 1c,d). For both species, the variation among geographical groups was also significantly large (Table 2). Mismatch distributions were computed for the three species, although the numbers of populations and individuals were low for Z. sicula. For the latter, the tests rejected both scenarios. Conversely, none of the demographic or spatial expansion scenarios could be rejected at the $5 \%$ level for Z. abelicea or Z. carpinifolia (Table 3). Taking into account the SSD values, a demographic scenario provided a better fit than a spatial expansion scenario for Z. abelicea,

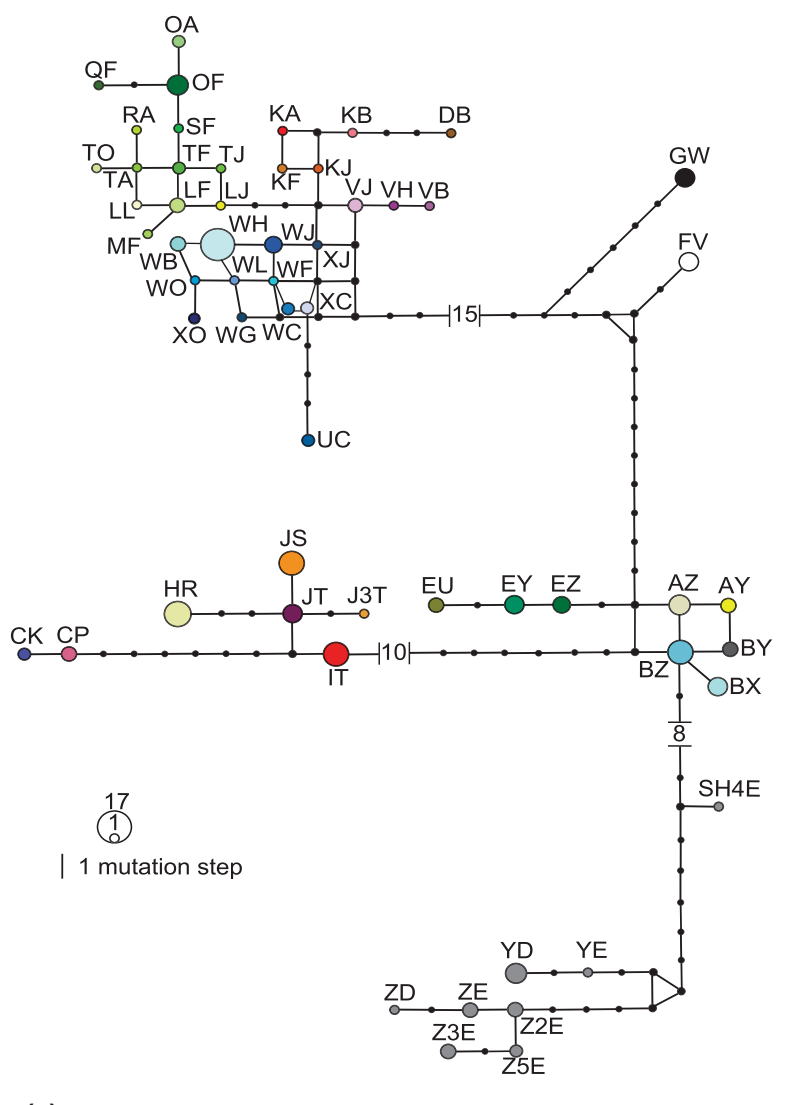

(a)
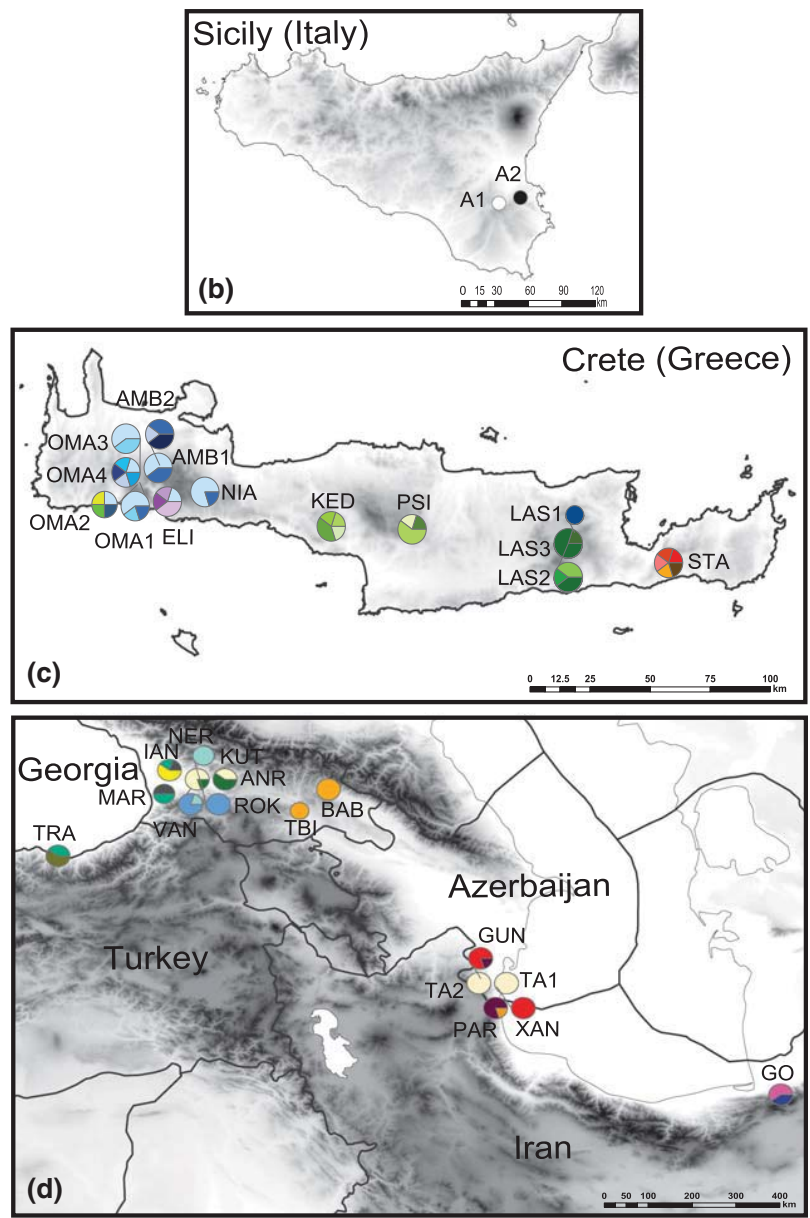

Figure 1 (a) Haplotype network based on the two chloroplast markers $\operatorname{trn} \mathrm{H}-p s b \mathrm{~A}$ and $\operatorname{trn} \mathrm{L}$ in three Eurasian Zelkova species. The name of each haplotype is constituted from the identifier of the $\operatorname{trn} \mathrm{H}-p s b \mathrm{~A}$ sequence followed by the identifier of the $\operatorname{trn} \mathrm{L}$ sequence, as given in Appendix S3. The size of each haplotype is proportional to the number of individuals that share it. The black dots without names on the lines are missing or non-sampled haplotypes. (b) Geographical distribution of Z. sicula haplotypes. (c) Geographical distribution of $Z$. abelicea haplotypes. (d) Geographical distribution of $Z$. carpinifolia haplotypes. 
Table $2 F_{\mathrm{ST}}$ and $F_{\mathrm{CT}}$ values for Zelkova abelicea, Z. carpinifolia and Z. sicula on the combined chloroplast data set (trn $\mathrm{H}-p s b \mathrm{~A}$ and $\operatorname{trn} \mathrm{L}$ ).

\begin{tabular}{|c|c|c|c|c|c|c|}
\hline Species & Source of variation & d.f. & Sum of squares & Variance component & Percentage of variation & $F$-indices \\
\hline \multirow[t]{4}{*}{ Zelkova abelicea } & Among groups & 3 & 94.112 & $V_{\mathrm{a}}=2.093$ & $59.26 \%$ & $F_{\mathrm{CT}}=0.593^{* *}$ \\
\hline & Among populations & 10 & 40.067 & $V_{\mathrm{b}}=0.685$ & $19.38 \%$ & $F_{\mathrm{ST}}=0.786^{* *}$ \\
\hline & Within populations & 53 & 40.000 & $V_{\mathrm{c}}=0.755$ & $21.36 \%$ & \\
\hline & Total & 66 & 174.179 & & & \\
\hline \multirow[t]{4}{*}{ Zelkova carpinifolia } & Among groups & 3 & 427.405 & $V_{\mathrm{a}}=8.456$ & $86.99 \%$ & $F_{\mathrm{CT}}=0.870^{* *}$ \\
\hline & Among populations & 12 & 60.166 & $V_{\mathrm{b}}=0.986$ & $10.14 \%$ & $F_{\mathrm{ST}}=0.971^{\star \star}$ \\
\hline & Within populations & 61 & 17.000 & $V_{\mathrm{c}}=0.279$ & $2.87 \%$ & \\
\hline & Total & 76 & 504.571 & & & \\
\hline \multirow[t]{3}{*}{ Zelkova sicula } & Among populations & 1 & 15.000 & $V_{\mathrm{a}}=0.300$ & $1.00 \%$ & $F_{\mathrm{ST}}=1.000^{*}$ \\
\hline & Within populations & 8 & 0.000 & $V_{\mathrm{b}}=0.000$ & $0.00 \%$ & \\
\hline & Total & 9 & 15.000 & & & \\
\hline
\end{tabular}

${ }^{\star} P<0.01 ;{ }^{* *} P<0.001$.

Table 3 Probabilities for a demographic or a spatial expansion that occurred $T$ generations ago ( $T$ in million generations ago, MGA) computed on the combined chloroplast data set $(\operatorname{trn} \mathrm{H}-p s b \mathrm{~A}$ and $\operatorname{trn} \mathrm{L})$ from three species of Zelkova.

\begin{tabular}{|c|c|c|c|c|c|c|}
\hline \multirow[b]{2}{*}{ Scenario } & \multicolumn{3}{|c|}{ Spatial expansion } & \multicolumn{3}{|c|}{ Demographic expansion } \\
\hline & $P$-values & SSD & $\tau=2 \mu T$ & $P$-values & SSD & $\tau=2 \mu T$ \\
\hline Zelkova abelicea & 0.475 & 0.0110 & 3.2 & 0.784 & 0.0056 & 8.0 \\
\hline West (Lefka Ori) ${ }^{\star *}$ & 0.553 & 0.0094 & 1.7 & 0.662 & 0.0073 & 3.1 \\
\hline Central West (Psiloritis) & 0.484 & 0.0127 & 2.0 & 0.526 & 0.0127 & 2.0 \\
\hline Central East (Dikti)** & 0.813 & 0.0012 & 1.0 & 0.844 & 0.0013 & 1.0 \\
\hline East (Thrypti) & 0.566 & 0.0471 & 1.9 & 0.600 & 0.0471 & 1.9 \\
\hline Zelkova carpinifolia & 0.633 & 0.0146 & 19.2 & 0.336 & 0.0268 & 0.0 \\
\hline West (Turkey \& Georgia) & 0.808 & 0.0011 & 1.2 & 0.012 & 0.0689 & - \\
\hline Central West (Georgia) & $\mathrm{n} / \mathrm{a}^{*}$ & $\mathrm{n} / \mathrm{a}$ & $\mathrm{n} / \mathrm{a}$ & $\mathrm{n} / \mathrm{a}$ & $\mathrm{n} / \mathrm{a}$ & $\mathrm{n} / \mathrm{a}$ \\
\hline Central East (Azerbaijan) & 0.175 & 0.0663 & 4.5 & 0.077 & 0.1038 & 5.3 \\
\hline East (Iran) & 0.310 & 0.0543 & 0.9 & 0.505 & 0.0543 & 0.9 \\
\hline Zelkova sicula & 0.008 & 0.2284 & - & 0.046 & 0.3675 & - \\
\hline
\end{tabular}

${ }^{*}$ n/a: not available due to the lack of polymorphism within the region. ${ }^{*}$ Without the two populations that showed signs of long-distance dispersal (OMA2 and LAS1). SSD, sum of the squared differences.

whereas the reverse was true for Z. carpinifolia (Table 3). When computed on the different regions within species, the results were found to be in agreement (Table 3), except for the western part of the distribution range of $Z$. carpinifolia.

For $Z$. abelicea, the correlation between geographical and genetic distances was highly significant and positive whatever geographical distance was used, whereas Mantel tests were non-significant for Z. carpinifolia at the 5\% level (Table 4).

\section{Nuclear genotype diversity and population differentiation}

ITS1 and ITS2 had consensus alignments of $381 \mathrm{bp}$ and 434 bp, respectively (Appendix S3). The two matrices display 12 polymorphic sites for ITS1 and 6 for ITS2. For ITS1, 24 genotypes were recorded and PHASE identified 21 different ribotypes, whose GC contents ranged between $60.6 \%$ and $61.7 \%$, with no significant differences among species. Only one ribotype is shared among the three species (ITS1_F; Table 1, Fig. 2a). For ITS2, a total of nine genotypes were found, consisting of eight ribotypes (Table 1). The GC contents were more variable and ranged between 54.2\% and $64.3 \%$, but did not differ significantly among species. The conserved motifs M2 and M3 were found in all ribotypes. Three ribotypes were shared: ITS1_F (Z. sicula,

Table 4 Mantel tests for Zelkova abelicea and Z. carpinifolia using chloroplast pairwise $F_{\mathrm{ST}}$ as the genetic distance.

\begin{tabular}{lllc}
\hline Units of distance & Measurement & Z. abelicea & Z. carpinifolia \\
\hline $\mathrm{km}$ & $\begin{array}{c}\text { Correlation } \\
\text { coefficient }\end{array}$ & 0.404 & -0.027 \\
$\log (\mathrm{km})$ & $\begin{array}{c}P \text { (random } \geq \\
\text { observed })\end{array}$ & $\mathbf{0 . 0 0 3}$ & 0.614 \\
& $\begin{array}{c}\text { Correlation } \\
\text { coefficient }\end{array}$ & 0.399 & 0.016 \\
& $\begin{array}{c}P(\text { random } \geq \\
\text { observed })\end{array}$ & $\mathbf{0 . 0 0 1}$ & 0.480 \\
\hline
\end{tabular}

$P($ random $\geq$ observed) is the percentage of correlations calculated on randomized data that are higher than the observed correlation. Values in bold are significant at least at the $1 \%$ level. 
Z. abelicea and Z. carpinifolia), ITS2_B (Z. sicula and Z. abelicea) and ITS2_E (Z. sicula and Z. carpinifolia) (Appendix S3).

ITS ribotype richness was similar in $Z$. abelicea and $Z$. carpinifolia ( $R s=3.9$ and $R s=3.0$, respectively), but still lower than the six ribotypes found in population A1 of $Z$. sicula (Table 1). Contrasting results were obtained for ITS1 and ITS2: whereas most populations of the three species are monomorphic for ITS2, higher diversity is recorded for ITS1. This is particularly true for Z. abelicea (12 polymorphic populations for ITS1 versus one for ITS2) and for $Z$. carpinifolia (nine polymorphic populations for ITS1 versus two for ITS2; Table 1). For Z. sicula, four ribotypes were found in ITS1, and six in ITS2. Gene diversity was higher in
Z. sicula than in Z. abelicea and Z. carpinifolia (Table 1), and nucleotide diversities were higher in $Z$. carpinifolia than in Z. abelicea, with Z. sicula again showing the highest value.

The ribotype MJNs display different patterns for ITS1 and ITS2 (Fig. 2a,b). For ITS1, all the ribotypes for the three studied species are derived from two sequences from Zelkova serrata (Zse3 and Zse4). Ribotype F, which is shared among the three species, is in an internal position and gives rise to most of the other ribotypes (except A, D, H and G). The ribotypes seen in $Z$. sicula (population A1) are close to those of $Z$. abelicea. The ribotypes seen in Z. carpinifolia are clustered into two groups, one branching directly from ribotype $\mathrm{F}$ and the other branching off from the $Z$. serrata

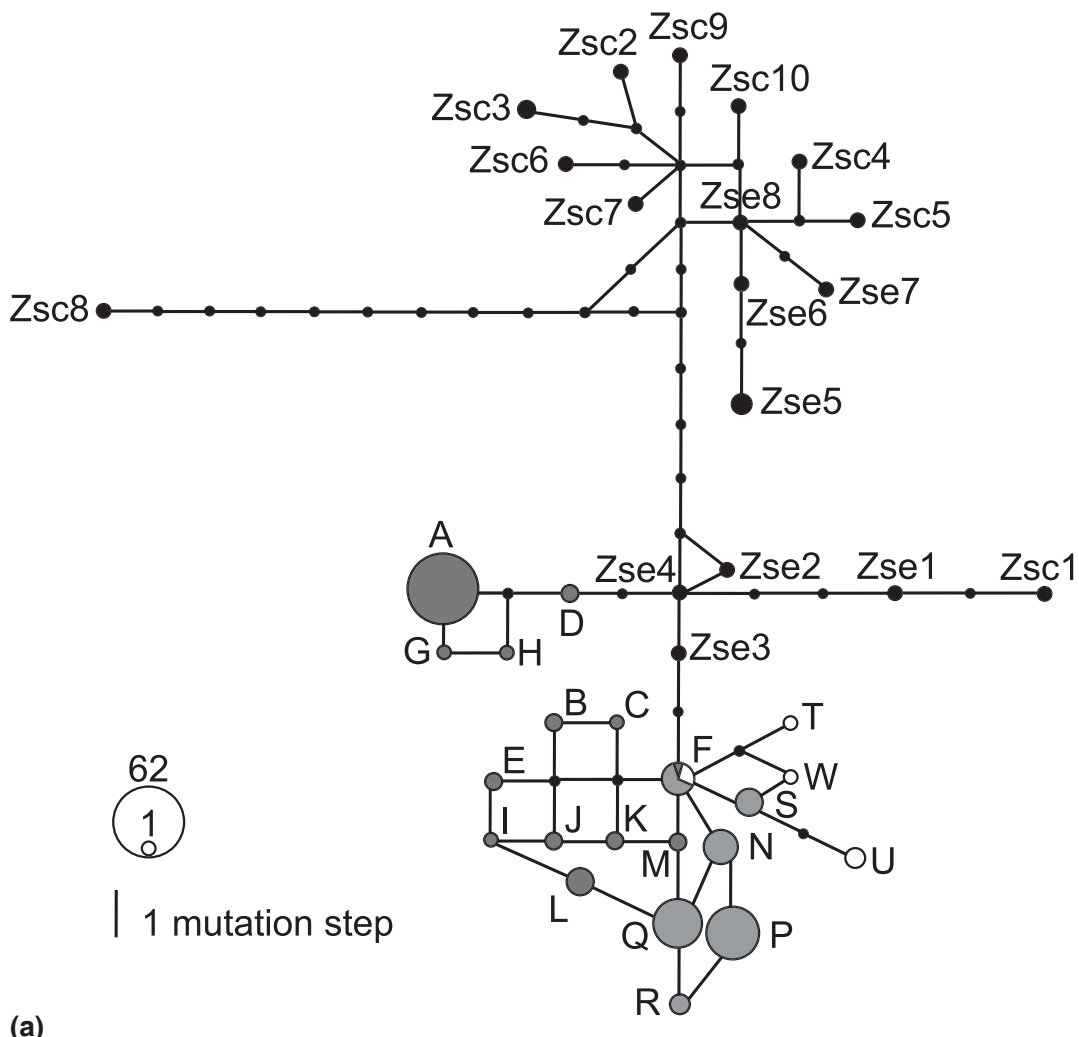

(a)

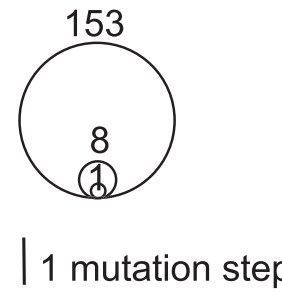

(b)

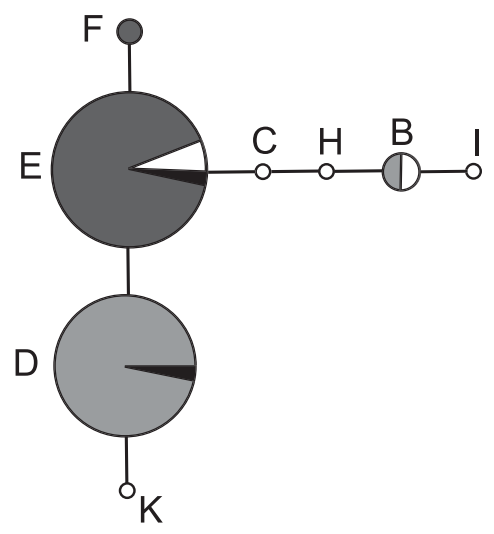

Figure 2 Median joining network for ribotypes of the nuclear ITS1 (a) and ITS2 (b) in six Eurasian Zelkova species. The size of each ribotoype is proportional to the number of individuals that share it and ribotypes are coloured according to the species they belong to (light grey, $Z$. abelicea; dark grey, $Z$. carpinifolia; white, $Z$. sicula; black, $Z$. schneideriana, Z. serrata and $Z$. sinica). For $Z$. serrata, Zse1-8 refer to GenBank accessions AJ622874, AJ622875, AJ622876, AJ622877, AJ622870, AJ622873, AJ622868 and AJ622869, respectively. For Z. schneideriana, Zsc1-10 refer to GenBank accessions AJ622867, AJ622860, AJ622858, AJ622861, AJ622862, AJ622857, AJ622864, AJ622856, AJ622865 and AJ622866, respectively. The black dots without names on the lines are missing or non-sampled ribotypes. 
ribotype Zse4. The ribotypes seen in $Z$. serrata are found in the middle of the network (Zse1 to Zse4), or (Zse5 to Zse8) close to those in $Z$. schneideriana. For ITS2, two ribotypes are predominant ( $\mathrm{D}$ and $\mathrm{E}$ ), with only one mutation separating them. Ribotype $\mathrm{K}$ of $Z$. sicula is derived from ribotype $\mathrm{D}$, which is predominantly found in $Z$. abelicea, whereas ribotypes $\mathrm{C}, \mathrm{H}, \mathrm{B}$ and $\mathrm{I}$, also from $Z$. sicula, are serially derived from ribotype $\mathrm{E}$, which is found predominantly in $Z$. carpinifolia but also in $Z$. sinica and $Z$. scheideriana. Differentiation indices within species were significant for $Z$. abelicea and $Z$. carpinifolia (Z. abelicea: $F_{\mathrm{ST}}=0.29, P<0.001 ; Z$. carpinifolia: $\left.F_{\mathrm{ST}}=0.26, P<0.05\right)$

\section{DISCUSSION}

\section{An overall high molecular diversity}

A very large number of chloroplast haplotypes was found in each of $Z$. abelicea and $Z$. carpinifolia, coupled with significant genetic structure. Such high numbers of haplotypes are seldom found in tree species (but see Fukatsu et al., 2012, for Z. serrata), even in species that are thought to have diversified long ago (Magri et al., 2007; Rodríguez-Sánchez et al., 2009; Caetano \& Naciri, 2011). Tree species are usually characterized by long generation times and low mutation rates (Petit \& Hampe, 2006). Such high diversity suggests an ancient origin of the species and limited genetic drift through time. In contrast, the history of $Z$. sicula is clearly marked by one or more severe bottlenecks.

Structured diversity was found for ITS, and especially for ITS1. In contrast with the chloroplast haplotypes however, some ribotypes are shared among species. ITS is known to have a multicopy structure, and hundreds or thousands of copies are generally found in a typical plant genome. The amplified sequence is therefore the consensus of many targets in the cell (Poczai \& Hyvönen, 2010). Intragenomic polymorphism due either to heterozygosity or to paralogy was recorded in all three species for ITS1 but only in Z. sicula for ITS2. For ITS1, a particularly stable GC content was recorded both among and within species, indicating that no pseudogenes were amplified. More variation among species in GC content was recorded for ITS2, but the variation within species was very low, except for $Z$. sicula, which had one ribotype (ITS2_C) with a higher GC content than average. Nonetheless, no pseudogenes could be clearly identified, as all the sequences contained the two highly conserved motifs M2 and M3. For ITS1 and ITS2, the mean GC contents $(61 \%$ and $59 \%$, respectively) were found to be at the lower end of the range of those recorded in other genera (Grimm \& Denk, 2008; Hřibová et al., 2011). The discrepancy between ITS1 and ITS2 variability, as observed in Zelkova, is probably due to ITS2 experiencing stronger constraints than ITS1 due to its secondary structure (Coleman, 2007; Hřibová et al., 2011).

A number of authors have highlighted the fact that ITS can be used to trace events of polyploidization or hybridization (Mayol \& Rosselló, 2001; Nieto Feliner \& Rosselló,
2007; Grimm \& Denk, 2008; Hřibová et al., 2011). Buckler et al. (1997) indicated that heterogeneity in the ITS sequence is more frequently found in organisms that are either hybrids or polyploids. We will therefore use the chloroplast data to infer species phylogeography, because chloroplasts are exclusively inherited through seeds, the vectors of colonization. ITS sequences will be used to better understand the role of past hybridization and polyploidization in the genus Zelkova.

\section{Zelkova abelicea: diversification and structuring}

Zelkova abelicea has a high level of genetic variation, as reported by Fineschi et al. (2004), and a high proportion of polymorphic populations (93\%), indicating that the colonization of Crete is ancient. Most populations (57\%) are found in the Lefka Ori massif and host $48 \%$ of the haplotypes. The genetic diversity of $Z$. abelicea is structured according to the four mountain chains of the island (Fig. 1c), with signs of isolation by distance, as indicated by Mantel tests; $59 \%$ of the total genetic variance is explained by variation among the four massifs, which indicates that gene flow mediated by seeds must have been negligible for a long time. This is corroborated by the fact that seed dispersal in Zelkova occurs only over short distances (Wang et al., 2001). Only two populations have haplotypes that are not consistently clustered with geography (LAS1 and OMA2; Fig. 1c): this might be the result of long-distance dispersal events (LDD), mediated by animals or humans. A demographic expansion scenario is more likely for $Z$. abelicea than a spatial expansion scenario. The $F_{S}$ statistic further supports this demographic hypothesis, as Fu (1997) noticed that this statistic is very sensitive to demographic expansion, which usually leads to large negative $F_{S}$ values, as recorded here.

By the early Miocene (12-23 Ma), Crete had already emerged and was separated by a sea, at its northern edge, from the lowland that occupied almost all of the current Aegean Sea (Triantis \& Mylonas, 2009). At the end of the Miocene and during the Pliocene $(2-12 \mathrm{Ma})$, most of the Aegean region was flooded, and Crete was isolated and split into three islands, corresponding to the Lefka Ori mountains, the Psiloritis massif and the Dikti/Thrypti region. Whereas the colonization of Crete by $Z$. abelicea probably took place before the early Miocene, the latter period might be the time at which population structuring began. When calculated for the four regions separately, the demographic scenario was also supported. When excluding populations that may have been founded by LDD events, Lefka Ori may have been the first massif where Z. abelicea experienced a demographic expansion, according to estimates of $\tau$ (Table 3 ).

\section{Zelkova carpinifolia: diversification and massive extinctions}

This species is the second most diverse of the three, displaying 15 haplotypes clustered into two equal groups separated 
by 19 mutations. This diversity translates into the highest nucleotide diversity recorded for the three species, although the gene diversity and haplotype richness are similar to those of $Z$. abelicea. Because $56 \%$ of the populations are monomorphic, $F_{\mathrm{ST}}$ is also high. This lack of within-population diversity might be a sign of past spatial expansions with haplotype surfing (Excoffier \& Ray, 2008). Accordingly, the spatial scenario is preferred to the demographic one; the nonsignificant Mantel test also supports this hypothesis.

One of the peculiarities of $Z$. carpinifolia is the large gap between the two haplotype clusters: the first comprises all eastern populations from the Hyrcanian region (Talysh and Alborz mountains), and the second comprises all the western populations from the Colchic region (western Georgia and north-eastern Turkey). These correspond to two known biogeographical regions, separated by a geographical barrier (Browicz, 1982). The large mutational gap between the two clusters suggests a very ancient history of diversification followed by extinctions that erased all the intermediate haplotypes. This can be interpreted as the footprint of a more wide-ranging ancestral species that occupied nearly all of the Northern Hemisphere during the Miocene and then became fragmented following climate changes. Alternative explanations could be LDD or chloroplast capture. LDD would introduce some incongruence between geographical distribution and haplotype genetic distance, which is clearly not the case, and chloroplast capture usually involves one haplotype rather than a whole cluster of haplotypes. The hypothesis that is most strongly supported is therefore that of an initial intraspecific polymorphism previously far more important than that recorded now. This corresponds to a clear genetic characteristic of a relict species.

Our molecular results fail to support the taxonomic distinctiveness of populations from the Talysh mountains (GUN), described as Z. hyrcana, or that of the population from Trabzon in Turkey (TRA), described as Z. carpinifolia subsp. yamraensis.

\section{Zelkova sicula: a result of ancient hybridization?}

Zelkova sicula has very characteristic patterns for both types of markers. The two known populations are both characterized by a unique chloroplast haplotype. The two haplotypes are separated by several mutations and are located between those of $Z$. abelicea and Z. carpinifolia. As this species is triploid and clonal, the two populations may have developed from a very small number of individuals.

Zelkova sicula might be of hybrid origin with parents close to the ancestral species of $Z$. abelicea and Z. carpinifolia. Accordingly, incomplete concerted evolution was found for ITS2, which is otherwise highly conserved, and this concurs with other studies that demonstrate higher ITS polymorphism in species of hybrid origin (Poczai \& Hyvönen, 2010). Fossil leaves dating from 300,000 вр in Italy (Riano Romano) and from Miocene-Pliocene deposits in France (Lac Chambon) were attributed to Z. carpinifolia and then later interpreted as being from Z. sicula once this species had been described (Nakagawa et al., 1998). The leaf morphology of the two populations supports the hybrid origin, with population A1 being closer to $Z$. abelicea and population A2 closer to Z. carpinifolia (Rucinska, 2012). Accordingly, we found that some ITS1 and ITS2 ribotypes in population A1 are identical to those of $Z$. abelicea whereas the ITS2 ribotype of population A2 is similar to that of Z. carpinifolia.

According to pollen records (Follieri et al., 1998; Magri et al., 2010), Zelkova expanded in the Italian Peninsula during the last interglacial period. It is thought to have disappeared from this region $31,000 \mathrm{BP}$, having been abundant between 128,000 and 75,000 вP (Follieri et al., 1986, 1988). Many populations from different ancestors could have persisted at times in refugia in Sicily, where Zelkova persisted in relative abundance until c. 20,000 вр (Sadori et al., 2008). Habitat disturbance is suspected to have increased the frequency of hybridization events, as reported for some alpine plants (Choler et al., 2004), and hybridization events might have occurred during one of the glacial cycles when the vegetation in Europe was forced to migrate southwards. This process must have been accompanied by strict bottlenecks, because only two haplotypes escaped extinction. Zelkova sicula is therefore an extremely important taxon and merits immediate conservation action.

\section{CONCLUSIONS}

Our results have addressed the three main questions we identified. First, the genus can be divided into two main groups: the south-western Eurasian group, comprising Z. sicula, Z. abelicea and Z. carpinifolia; and the East Asian group, comprising $Z$. sinica, $Z$. serrata and $Z$. schneideriana. Zelkova carpinifolia is genetically closer the East Asian taxa according to chloroplast markers. The three south-western Eurasian species have haplotypes that are distinctly clustered according to species assignment.

Second, although Z. abelicea covers a relatively small geographical area, it is highly genetically diverse within each of the four mountain massifs where it occurs, representing separate genetic units. For $Z$. carpinifolia, two main clades were identified, an eastern clade in Azerbaijan and Iran, including the highly isolated population in eastern Georgia, and a western clade in western Georgia and north-eastern Turkey. The large gap between the two clusters suggests a very ancient history of diversification followed by widespread extinctions. Zelkova sicula was confirmed to be genetically impoverished and is suspected to have a hybrid origin with parents that were close to the widespread ancestral species of $Z$. abelicea and $Z$. carpinifolia. This assumption needs further investigation, and additional molecular markers are required to better test this hypothesis.

Third, haplotype and ribotype diversities showed similar trends for Z. abelicea and Z. carpinifolia. Discrepancies between the chloroplast and nuclear data sets exist, such as 
ITS2 showing reduced diversity, probably due to strict evolutionary constraints, or the south-western Eurasian group being closer to $Z$. serrata for ITS1, in agreement with Denk \& Grimm (2005). Moreover, the ITS data set suggests a putative hybrid origin for Z. sicula, a conclusion that would have not been retrieved from the chloroplast markers alone.

Our results provide a unique tool for both in situ and ex situ approaches aimed at conserving the genetic diversity in Zelkova, which represent a significant evolutionary heritage (Petit et al., 2005a).

\section{ACKNOWLEDGEMENTS}

We thank the Franklinia Foundation for its generous financial support and the many botanical gardens that provided samples: Sir Harold Hillier Garden (UK), Morris Arboretum (USA), Bonn Botanical Garden (Germany), Kutaisi Botanical Garden (Georgia), the Botanical Garden of Adelaide (Australia), the Kornik Arboretum of the Polish Academy of Sciences and Botanical Garden of the University of Poznan (Poland), le Jardin Botanique de Strasbourg (France). We also thank Benoît Clément and Susanne Bollinger (Botanical Garden of the University of Fribourg, Switzerland), Emanuel Gerber, André Fasel and Rolland Keller (Natural History Museum Fribourg, Switzerland), Yann Marbach, Laurence Fazan and Bernhard Egli for their assistance during fieldwork and Michelle Price for checking the English. We give special thanks to Joachim Gratzfeld and Douglas Gibbs from the BGCI, who coordinated the data and sample exchange, and to Valida Ali-zade, Esmira Alirzayeva (Azerbaijan National Academy of Sciences), Hajiaga Safarov (Hyrcan National Park, Azerbaijan), Mohammad Jafari (University of Teheran, Iran) and Ilhan Kaya (Yuzuncuyil University, Turkey) for fieldwork coordination and sampling in Azerbaijan, Iran and Turkey. The permission to collect $Z$. abelicea was granted by the Ministry of the Environment, General Directorate of Forests, Department of Aesthetic Forests, and National Parks and Wildlife Management, Greece (199076/1843).

\section{REFERENCES}

Bandelt, H.J., Forster, P. \& Röhl, A. (1999) Median-joining networks for inferring intraspecific phylogenies. Molecular Biology and Evolution, 16, 37-48.

Browicz, K. (1982) Chorology of trees and shrubs in south-west Asia and adjacent regions, Vol. 1. Polish Scientific Publishers, Warsaw.

Buckler, E.S., Ippolito, A. \& Holtsford, T.P. (1997) The evolution of ribosomal DNA: divergent paralogues and phylogenetic implications. Genetics, 145, 821-832.

Burnham, R.J. (1986) Foliar morphological analysis of the Ulmoideae (Ulmaceae) from the early Tertiary of western North America. Palaeontographica Abteilung B, 201, 135-167.
Caetano, S. \& Naciri, Y. (2011) The biogeography of seasonally dry tropical forests in South America. Seasonally dry tropical forests: ecology and conservation (ed. by R. Dirzo, H.S. Young, H.A. Mooney and G. Ceballos), pp. 23-44. Island Press, Stanford, CA.

Choler, P., Erschbamer, B., Tribsch, A., Gielly, L. \& Taberlet, P. (2004) Genetic introgression as a potential to widen a species' niche: insights from alpine Carex curvula. Proceedings of the National Academy of Sciences USA, 101, 171-176.

Coleman, A.W. (2007) Pan-eukaryote ITS2 homologies revealed by RNA secondary structure. Nucleic Acids Research, 35, 3322-3329.

Connor, S.E. (2009) Human impact - the last nail in the coffin for ancient plants? Journal of Biogeography, 36, 485486.

Davis, P. (1982) Flora of Turkey and the East Aegean Islands. Edinburgh University Press, Edinburgh, UK.

Denk, T. \& Grimm, G.W. (2005) Phylogeny and biogeography of Zelkova (Ulmaceae sensu stricto) as inferred from leaf morphology, ITS sequence data and the fossil record. Botanical Journal of the Linnean Society, 147, 129-157.

Denk, T., Grimm, G., Stögerer, K., Langer, M. \& Hemleben, V. (2002) The evolutionary history of Fagus in western Eurasia: evidence from genes, morphology and the fossil record. Plant Systematics and Evolution, 232, 213-236.

Di Pasquale, G., Garfi, G. \& Quézel, P. (1992) Sur la présence d'un Zelkova nouveau en Sicile sud orientale (Ulmaceae). Biocosme Mésogéen, 8-9, 401-409.

Egli, B. (1997) A project for the preservation of Zelkova abelicea (Ulmaceae), a threatened endemic tree species from the mountains of Crete. Bocconea, 5, 505-510.

Excoffier, L. (2004) Patterns of DNA sequence diversity and genetic structure after a range expansion: lessons from the infinite-island model. Molecular Ecology, 13, 853-864.

Excoffier, L. \& Ray, N. (2008) Surfing during population expansions promotes genetic revolutions and structuration. Trends in Ecology and Evolution, 23, 347-351.

Excoffier, L., Smouse, P.E. \& Quattro, J.M. (1992) Analysis of molecular variance inferred from metric distances among DNA haplotypes - application to human mitochondrialDNA restriction data. Genetics, 131, 479-491.

Excoffier, L., Laval, G. \& Schneider, S. (2006) Arlequin ver. 3.1: an integrated software for population genetic data analysis. University of Bern, Switzerland. Available at: http://cmpg.unibe.ch/software/arlequin3.

Fazan, L., Stoffel, M., Frey, D.J., Pirintsos, S. \& Kozlowski, G. (2012) Small does not mean young: age estimation of severely browsed trees in anthropogenic Mediterranean landscapes. Biological Conservation, 153, 97-100.

Fineschi, S., Anzidei, M., Cafasso, D., Cozzolino, S., Garfi, G., Pastorelli, R., Salvini, D., Taurchini, D. \& Vendramin, G.G. (2002) Molecular markers reveal a strong genetic differentiation between two European relic tree species: Zelkova abelicea (Lam.) Boissier and Z. sicula Di Pasquale, Garfi \& Quézel (Ulmaceae). Conservation Genetics, 3, 145-153. 
Fineschi, S., Cozzolino, S., Migliaccio, M. \& Vendramin, G.G. (2004) Genetic variation of relic tree species: the case of Mediterranean Zelkova abelicea (Lam.) Boissier and Z. sicula Di Pasquale, Garfi and Quézel (Ulmaceae). Forest Ecology and Management, 197, 273-278.

Follieri, M., Magri, D. \& Sadori, L. (1986) Late Pleistocene Zelkova extinction in Central Italy. New Phytologist, 103, 269-273.

Follieri, M., Magri, D. \& Sadori, L. (1988) 250,000-year pollen record from Valle di Castiglione (Roma). Pollen et Spores, 30, 329-356.

Follieri, M., Giardini, M., Magri, D. \& Sadori, L. (1998) Palynostratigraphy of the last glacial period in the volcanic region of Central Italy. Quaternary International, 47-48, $3-20$.

Fu, Y.-X. (1997) Statistical tests of neutrality of mutations against population growth, hitchhiking and background selection. Genetics, 147, 915-925.

Fukatsu, E., Watanabe, A., Nakada, R., Isoda, K., Hirao, T., Ubukata, M., Koyama, Y., Kodani, J., Saito, M., Miyamoto, N. \& Takahashi, M. (2012) Phylogeographical structure in Zelkova serrata in Japan and phylogeny in the genus Zelkova using the polymorphisms of chloroplast DNA. Conservation Genetics, 13, 1109-1118.

Garfi, G. (2006) Zelkova sicula. IUCN Red List of Threatened Species. Version 2010.4. International Union for Conservation of Nature and Natural Resources, Gland, Switzerland. Available at: http://www.iucnredlist.org/details/61678/0 (accessed April 2013).

Garfi, G., Barbero, M. \& Tessier, L. (2002) Architecture and growth patterns of Zelkova sicula (Ulmaceae) in south-east Sicily as a response to environmental conditions. Journal of Mediterranean Ecology, 3, 65-76.

Garfi, G., Carimi, F., Pasta, S., Rühl, R. \& Trigila, S. (2011) Additional insights on the ecology of the relic tree Zelkova sicula di Pasquale, Garfi et Quézel (Ulmaceae) after the finding of new population. Flora, 206, 407-417.

Grimm, G.W. \& Denk, T. (2008) ITS evolution in Platanus (Platanaceae): homoeologues, pseudogenes and ancient hybridization. Annals of Botany, 101, 403-419.

Güner, A. \& Zielinski, J. (1998) Zelkova carpinifolia. IUCN Red List of Threatened Species. Version 2010.4. International Union for Conservation of Nature and Natural Resources, Gland, Switzerland. Available at: http://www. iucnredlist.org/details/31303/0 (accessed April 2013).

Hall, T.A. (1999) BioEdit: a user-friendly biological sequence alignment editor and analysis program for Windows 95/ 98/NT. Nucleic Acids Symposium Series, 41, 95-98.

Hewitt, G.M. (2000) The genetic legacy of Quaternary ice ages. Nature, 405, 907-913.

Hřibová, E., Čížková, J., Christelová, P., Taudien, S., de Langhe, E. \& Doležel, J. (2011) The ITS1-5.8S-ITS2 sequence region in the Musaceae: structure, diversity and use in molecular phylogeny. PLoS ONE, 6, e17863.

Ingvarsson, K., Ribstein, S. \& Taylor, D.R. (2003) Molecular evolution of insertions and deletion in the chloroplast gen- ome of Silene. Molecular Ecology and Evolution, 20, 17371740.

Kozlowski, G., Gibbs, D., Huan, F., Frey, D. \& Gratzfeld, J. (2012) Conservation of threatened relict trees through living ex situ collections: lessons from the global survey of the genus Zelkova (Ulmaceae). Biodiversity and Conservation, 21, 671-685.

Kozlowski, G., Frey, D., Fazan, L., Egli, B., Bétrisey, S., Gratzfeld, J., Garfi, G. \& Pirintsos, S. (2014) The Tertiary relict tree Zelkova abelicea (Ulmaceae): distribution, population structure and conservation status. Oryx, 48, 80-87.

Magri, D., Fineschi, S., Bellarosa, R., Buonamici, A., Sebastiani, F., Schirone, B., Simeone, M.C. \& Vendramin, C.C. (2007) The distribution of Quercus suber chloroplast haplotypes matches the paleogeographical history of the western Mediterranean. Molecular Ecology, 16, 5259-5266.

Magri, D., Di Rita, F. \& Palombo, M.R. (2010) An early Pleistocene interglacial record from an intermontane basin of central Italy (Scoppito, L'Aquila). Quaternary International, 225, 106-113.

Mai, D.H. (1995) Tertiäre Vegetationsgeschichte Europas. Methoden und Ergebnisse. Gustav Fischer, Jena, Germany.

Mayol, M. \& Rosselló, J.A. (2001) Why nuclear ribosomal DNA spacers (ITS) tell different stories in Quercus. Molecular Pylogenetics and Evolution, 19, 167-176.

Milne, R.I. \& Abbott, R.J. (2002) The origin and evolution of Tertiary relict floras. Advances in Botanical Research, 38, 281-314.

Nakagawa, T., Garfi, G., Reille, M. \& Verlaque, R. (1998) Pollen morphology of Zelkova sicula (Ulmaceae), a recently discovered relic species of the European Tertiary flora: description, chromosomal relevance, and palaeobotanical significance. Review of Palaeobotany and Palynology, 100, 27-37.

Nei, M. (1987) Molecular evolutionary genetics. Columbia University Press, New York.

Nieto Feliner, G. \& Rosselló, J.A. (2007) Better the devil you know? Guidelines for insightful utilization of nrDNA ITS in species-level evolutionary studies in plants. Molecular Phylogenetics and Evolution, 44, 911-919.

Petit, R.J. \& Hampe, A. (2006) Some evolutionary consequences of being a tree. Annual Review of Ecology, Evolution, and Systematics, 37, 187-214.

Petit, R.J., El Mousadik, A. \& Pons, O. (1998) Identifying populations for conservation on the basis of genetic markers. Conservation Biology, 12, 844-855.

Petit, R.J., Hampe, A. \& Cheddadi, R. (2005a) Climate changes and tree phylogeography in the Mediterranean. Taxon, 54, 877-885.

Petit, R.J., Duminil, J., Fineschi, S., Hampe, A., Salvini, D. \& Vendramin, G.G. (2005b) Comparative organization of chloroplast, mitochondrial and nuclear diversity in plant populations. Molecular Ecology, 14, 689-701.

Phitos, D., Strid, A., Snogerup, S. \& Greuter, W. (eds) (1995) The red data book of rare and threatened plants of Greece. WWF Greece, Athens, Greece. 
Poczai, P. \& Hyvönen, J. (2010) Nuclear ribosomal spacer regions in plant phylogenetics: problems and prospects. Molecular Biology Reports, 37, 1897-1912.

Quézel, P. \& Médail, F. (2003) Écologie et biogeography des forêts du bassin méditerranéen. Elsevier, Paris.

Ray, N., Currat, M. \& Excoffier, L. (2003) Intra-deme molecular diversity in spatially expanding populations. Molecular Biology and Evolution, 20, 76-86.

Rodríguez-Sánchez, F., Guzmán, B., Valido, A., Vargas, P. \& Arroyo, J. (2009) Late Neogene history of the laurel tree (Laurus L., Lauraceae) based on phylogeographical analyses of Mediterranean and Macaronesian populations. Journal of Biogeography, 36, 1270-1281.

Rousset, F. (1997) Genetic differentiation and estimation of gene flow from $F$-statistics under isolation by distance. Genetics, 145, 1219-1228.

Rucinska, B. (2012) Systematyka europejskich i poludniowozachodnio azjatyckich taksonów rodzaju Zelkova Spach na podstawie wielocechowej analizy lisci. MSc Thesis. Faculty of Natural Sciences, Kazimierz Wielki University in Bydgoszcz, Poland.

Sadori, L., Zanchetta, G. \& Giardini, M. (2008) Last Glacial to Holocene palaeoenvironmental evolution at Lago di Pergusa (Sicily, southern Italy) as inferred by pollen, microcharcoal, and stable isotopes. Quaternary International, 181, 4-14.

Schönswetter, P., Stehlik, I., Holderegger, R. \& Tribsch, A. (2005) Molecular evidence for glacial refugia of mountain plants in the European Alps. Molecular Ecology, 14, 35473555.

Shaw, J., Lickey, E.B., Beck, J.T., Farmer, S.B., Liu, W., Miller, J., Siripun, K.C., Winder, C.T., Schilling, E.E. \& Small, R.L. (2005) The tortoise and the hare II: relative utility of 21 noncoding chloroplast DNA sequences for phylogenetic analysis. American Journal of Botany, 921, 142-166.

Simmons, M.P. \& Ochoterena, H. (2000) Gaps as characters in sequence-based phylogenetic analyses. Systematic Biology, 49, 369-381.

Søndergaard, P. \& Egli, B.R. (2006) Zelkova abelicea (Ulmaceae) in Crete: floristics, ecology, propagation and threats. Willdenowia, 36, 317-322.

Stephens, M., Smith, N.J. \& Donnelly, P. (2001) A new statistical method for haplotype reconstruction from population data. American Journal of Human Genetics, 68, 978989.

Taberlet, P., Gielly, L., Pautou, G. \& Bouvet, J. (1991) Universal primers for amplification of three non-coding regions of chloroplast DNA. Plant Molecular Biology, 17, 1105-1109.

Tajima, F. (1983) Evolutionary relationship of DNA sequences in finite populations. Genetics, 105, 437-460.
Terrab, A., Schönswetter, P., Talavera, S., Vela, E. \& Stuessy, T.F. (2008) Range-wide phylogeography of Juniperus thurifera L., a presumptive keystone species of western Mediterranean vegetation during cold stages of the Pleistocene. Molecular Phylogeny and Evolution, 48, 94-102.

Triantis, K.A. \& Mylonas, M. (2009) Greek islands, biology. Encyclopedia of islands (ed. by R. Gillespie and D.A. Clague), pp. 388-392. University of California Press, Ewing, NJ.

Walker, J.D., Geissman, J.W., Bowring, S.A. \& Babcock, L.E. (eds) (2012) GSA geologic time scale (v. 4.0). Geological Society of America, Boulder, CO. doi:10.1130/2012. CTS004R3C.

Wang, Y.-F., Ferguson, D.K., Zetter, R., Denk, T. \& Garfi, G. (2001) Leaf architecture and epidermal characters in Zelkova, Ulmaceae. Botanical Journal of the Linnean Society, 136, 255-265.

White, T.J., Bruns, T., Lee, S. \& Taylor, J.W. (1990) Amplification and direct sequencing of fungal ribosomal RNA genes for phylogenetics. PCR protocols: a guide to methods and amplifications (ed. by M.A. Innis, D.H. Gelfand, J.J. Sninsky and T.J. White), pp. 315-322. Academic Press, San Diego, CA.

\section{SUPPORTING INFORMATION}

Additional Supporting Information may be found in the online version of this article:

Appendix S1 The institutions and number of ex situ individuals of Zelkova schneideriana, $Z$. serrata and $Z$. sinica used in this study.

Appendix S2 Sequence names and source of primers.

Appendix S3 The substitutions and indels for the chloroplast haplotypes at the locus $t r n \mathrm{H}-p s b \mathrm{~A}$ and $\operatorname{trn} \mathrm{L}$, and for the nuclear ribotypes at ITS1 and ITS2. The number of individuals and the species identity are given for each haplotype and each ribotype.

Author contributions: Y.N. and G.K. developed the experimental ideas; D.F., E.M., G.G., S.P. and S.B. conducted the field work; C.C. analysed the samples under the supervision of Y.N.; and C.C, Y.N. and G.K. led the writing of the manuscript. 